Journal of Social Sciences 4 (4): 251-254, 2008

ISSN 1549-3652

(C) 2008 Science Publications

\title{
The Changes of Some Electrolytes after Two Months Activity
}

\author{
${ }^{1}$ Pourvaghar, M.J. and ${ }^{2}$ A.R. Shahsavar \\ ${ }^{1}$ Department of Physical Education, University of Kashan, Kashan, I.R. Iran \\ ${ }^{2}$ Department of Physical Education, University of Payame Noor (PNU), I.R. Iran
}

\begin{abstract}
Some investigators have speculated that sodium chloride losses in sweat associated with net dehydration may lead to the observed hyponatremia after prolong strenuous exercise. The effects of altered hydration can influence athletes cognitively in addition to physically. In this research, rest alterations of sodium and potassium of blood serum have been investigated. The subjects were male students who have been selected purposefully. Variables of height, weight, age and body mass index (BMI) have been measured too. Participants took part in the training of incremental continuous running for 2 times in a week for 2 months. The running distance for subjects had been planned before performing main protocol training. The heart rate was controlled by polar watches. In the first and last session of training, the subjects' oxygen consumption $\left(\mathrm{VO}_{2 \max }\right)$ was measured. The data analysis by means of paired sample t-test showed that: 1 . The subjects' sodium of serum had an increase of $2.21 \mathrm{mEq} / \mathrm{L}^{-1}$ even after $24 \mathrm{~h}$. Its reason can be due to the loss of water and body fluids in the final session of training.2. The subjects' potassium of rest serum had an increase of $0.13 \mathrm{~m} \mathrm{Eq} \mathrm{L}^{-1}$ that probably the extra- cellular potassium had returned into the intracellular. The observation suggested that accumulation of extra cellular potassium might be important for the development of fatigue in human muscles. We concluded that sodium of serum had an increased after $24 \mathrm{~h}$. Its reason can be due to the loss of water and body fluids in the final session of training. The subjects' potassium of rest serum had an increased that probably the extra-cellular potassium had returned into the intracellular. Also, this research recommends athletes must be used as dietary supplements in products designed to affect physical performance (ergogenic aids), their use should be considered.
\end{abstract}

Key words: $\mathrm{VO}_{2 \max }$, electrolyte, incremental continuous running

\section{INTRODUCTION}

Sodium is the major cation of the extracellular fluid. A reduction in the extracellular sodium concentration will result in a fluid shift into intracellular space, which can lead to cellular swelling and its associated complication ${ }^{[12]}$. It is overall eight to 10 times more concentrated in the extracellular than in the intracellular space. The sodium concentration gradient across the cellular membrance and the transmembrance sodium fluxes are regulated by the sodium-potassium pump, which plays an important role in cellular processes $^{[2]}$. Several hyponatremia (sodium $<130 \mathrm{~m}$ mol $\mathrm{L}^{-1}$ ) has been associated with several complications, including mild symptoms, such as malaise, nausea, fatigue and confusion. Hyponatremia is seldom observed in athletes after $4 \mathrm{~h}$ of exercise ${ }^{[12]}$. Several possible mechanisms have been postulated to lead to exercise induced hyponatremia ${ }^{[8]}$. Some investigators have speculated that sodium chloride losses in sweat associated with net dehydration may lead to the observed hyponatremia after prolong strenuous exercise $^{[12]}$.

Alteration in total sodium content and in transmembrance sodium flux rates occurs in numerous normal and disease conditions, including exercise muscle $^{[2]}$.

Hyponatremia develops when both sodium and fluid are lose in sweat, the loss of $120 \mathrm{mmol}$ of sodium and $1 \mathrm{~L}$ of fluid from the Extracellular Fluid (ECF), corresponding to a fluid loss of $3 \mathrm{~L}$ from the total body water, will cause the serum sodium concentration to ruse to $141 \mathrm{mmol} \mathrm{L}^{-1[10]}$. If the ECF volume decreases by $1.5 \mathrm{~L}$ rather than $1 \mathrm{~L}$, the serum concentration will

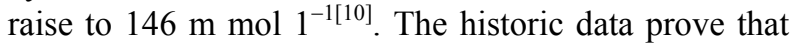
dehydration and unreplaced sodium losses during prolonged exercise cause hyponatremia ${ }^{[10]}$.

On the other hand, potassium, the major cation of the intracellular fluid, is released from muscle cells during exercise in direct relation to exercise

Corresponding Author: Pourvaghar, M.J. Department of Physical Education, Faculty of Humanities, University of Kashan, Kashan, I.R. Iran 
intensity $^{[3,12]}$. A rise in potassium (hyperkalaemia) is rapidly reversed after rest from exercise and many even associated with a lowering of potassium levels to below control levels (hyperkalaemia) ${ }^{[12]}$. The resultant of hyperkalaemia may also be due to increased blood flow to the skeletal muscles and/or increased intracellular $\operatorname{acidos}^{[12]}$. Barlow et al., showed that the exerciseinduced rise in potassium and ventilation are greater at matched sub maximal work rate in subjects with normal left ventricular function ${ }^{[1]}$. Another study showed that the exercise-induced rise in potassium at matched sub maximal work rate tended to be greater in severe chronic heart failure, but it did not reach statistical significance ${ }^{[13]}$. The $\Delta \mathrm{k}^{+}$from rest to peak exercise was correlated with peak $\mathrm{vo}_{2}$. The amount of potassium related into the circulation from the muscle is dependent on the magnitude of muscle contraction, as reflected by absolute workload ${ }^{[11]}$.

The observation suggested that accumulation of extracellular potassium might be important for the development of fatigue in human muscle ${ }^{[5,11]}$.

Mc kenna et al. found that the femoral arterial venous potassium difference. During intense cycle exercise was the same before and after training, suggesting that release of potassium to the blood stream was not changed by the training ${ }^{[7]}$.

In another research, observed that 8 weeks of onelegged endurance training (2h) reduced potassium release during exercise. Furthermore, the rise in plasma potassium in dogs induced by exercise was lower in dogs that had performed endurance training. Apparently, the intensity and duration of the exercise during training affects the potassium release during exercise $^{[6]}$. It is, however, unclear to what extent training affects $\mathrm{Na}^{+}$and $\mathrm{K}^{+}$how such changes may influence muscle interstitum potassium kinetics and performance. It is, however, not clear whether training induces changes in the amount of $\mathrm{K}^{+}$and $\mathrm{Na}^{+}$in rest and in exercise.

\section{MATERIALS AND METHODS}

In this semi-experimental research, the effect of 16 sessions of incremental continuous running on sodium and potassium concentration level of athletic subjects` rest time serum and maximal oxygen consumption $\left(\mathrm{VO}_{2 \max }\right)$ was studied. The subjects of this study were 14 students that had at least 3 years of experience in various trainings. The Means and standard deviations of their height, weight, age and Body Mass Index (BMI) were respectively: (175 \pm 5.9$), \quad(68.27 \pm 9.89)$, (19.56 \pm 1.16$),(22.08 \pm 2.47)$.

Training protocol: To evaluate rest time values of serum and potassium, in first stage, blood samples were taken from subjects at 8 in the morning on fasting condition, and exactly before the start of main program of research. After wards, 12 min running-jugging test were performed to determine $\mathrm{Vo}_{2}$ max. After $24 \mathrm{~h}$ of rest, the main training was program performed on Sunday and Tuesday of every week for 16 sessions with certain distance and heart rate (Table 1). Subjects warmed up for $15 \mathrm{~min}$ before each session. $24 \mathrm{~h}$ after last training session, the second stage of blood sampling was performed to measure the rest time serum potassium and sodium conditions. After wards, the 12 min running-jugging test was performed too.

- To determine the subjects' maximum heart rate formula 220 -age (year) was used

- To determine the training intensity polar clock (PU-801) (Made in Japan) was used

- For statistical analysis SPSS software and Word 2003 was used

- To find differences between means paired-sample $t$ test was used

- To determine sodium and potassium serum French Hycel system and Flame Photometry were used

Determination of maximal oxygen consumption (VO2 max): Blood sampling finished at $8 \mathrm{am}$. Also, variables of height, weight and blood pressure were measured and recorded by a physician (Table 2). Then, a $12 \mathrm{~min}$

Table 1: Training protocol designed for subjects

\begin{tabular}{llll}
\hline $\begin{array}{l}\text { Training } \\
\text { session }\end{array}$ & $\begin{array}{l}\text { Every session } \\
\text { distance }(\mathrm{m})\end{array}$ & $\begin{array}{l}\text { Train intensity } \\
\text { (max percent } \\
\text { of heart rate) }\end{array}$ & $\begin{array}{l}\text { Heart beat } \\
(\mathrm{min})\end{array}$ \\
\hline 1-4 sessions & 2000 & $70-75$ & $140-150$ \\
5-8 sessions & 2400 & $75-80$ & $150-160$ \\
9-12 sessions & 2800 & $80-85$ & $160-170$ \\
$13-16$ sessions & 3200 & $85-90$ & $170-180$ \\
\hline
\end{tabular}

Table 2: Descriptive indexes, means and standard deviations of subjects $(\mathrm{N}=14)$

\begin{tabular}{lll}
\hline Statistical index & Mean & S.D. \\
\hline Weight $(\mathrm{Kg})$ & 68.21 & 9.89 \\
Height $(\mathrm{cm})$ & 175.5 & 5.90 \\
Age $($ Year) & 19.56 & 1.16 \\
Body mass index (BMI) & 22.08 & 2.47 \\
\hline
\end{tabular}


J. Social Sci., 4 (4): 251-254, 2008

Table 3: Statistical variables of subjects in pre and post-test, $p$ and $t$ values

\begin{tabular}{|c|c|c|c|c|}
\hline Variables & Mean pre-test & Mean post-test & $\mathrm{t}$ value & $\mathrm{p}$ value \\
\hline ** Sodium $\left(\mathrm{m} \mathrm{Eq} \mathrm{L}{ }^{1}\right)$ & $139.43 \pm 1.58$ & $142.64 \pm 2.47$ & 3.29 & 0.006 \\
\hline Potassium $\left(\mathrm{m} \mathrm{Eq} \mathrm{L}^{1}\right)$ & $3.83 \pm 0.27$ & $3.96 \pm 0.23$ & 1.49 & 0.76 \\
\hline 12 Min running-jugging (m) & $2247.14 \pm 147.84$ & $2440.71 \pm 119.79$ & 4.88 & 0.0001 \\
\hline $\mathrm{Vo}_{2} \max \left(\mathrm{ml} \cdot \mathrm{Kg}^{-1} \cdot \mathrm{min}^{-1}\right)$ & $48.92 \pm 3.96$ & $54.11 \pm 3.21$ & 5.48 & 0.0001 \\
\hline
\end{tabular}

** It is significant in lower than 0.01 level

running-jugging test to determine $\mathrm{Vo}_{2}$ max, was performed. This test has been designed to measure the distance covered during $12 \mathrm{~min}$. The subjects were asked to run as much as they could during $12 \mathrm{~min}$, however, they were allowed to walk. The aim of this research has been to traverse the maximum possible distance during $12 \mathrm{~min}$. The measurement unit was meter. To find the subjects' $\mathrm{VO}_{2}$ max the following equation was used ${ }^{[9]}$ :

$$
\mathrm{VO}_{2 \max }\left(\mathrm{ml} \cdot \mathrm{kg}^{-1} \cdot \mathrm{min}^{-1}\right)=[0.0268+(\mathrm{D})]-11.3
$$

RESULTS: In Table 2, the means of subjects, standard Deviations of descriptive variables have been showed. In Table 3 the subjects rest time serum sodium and potassium variables and $\mathrm{t}$ and $\mathrm{P}$ values have been showed.

As observed in Table 3:

- Serum sodium concentration level has had significant difference in pre- and post-test in rest time condition after 2 months of training $(\mathrm{p}=$ 0.006 , $d f=13$ and $t=3.29$ ).

- Serum potassium concentration levels among subjects after 16 sessions of incremental continuous running and in rest time condition was not significantly different. $(p=0.16, d f=13$ and $t$ $=1.49$ ).

- On the other hand, comparing subjects' runningjugging test means showed significant differences after 16 sessions of training $(\mathrm{p}=0.0001, \mathrm{df}=13$ and $\mathrm{t}=4.88$ ).

- Also, comparing subjects maximal oxygen consumption means showed significant difference after 16 sessions of training $(\mathrm{p}=0.0001, \mathrm{df}=13$ and $\mathrm{t}=5.48$ ).

\section{DISCUSSION}

The purpose of this research has been to study serum sodium and potassium concentration variations in rest time condition. To do so, the subjects of research, participated in an incremental continuous running activity (Table 1). The results showed the sodium and potassium concentrations involved fluctuation even after $24 \mathrm{~h}$ from regular body activity and did not return to its original and base state.

The majority of researches done show that blood serum electrolyte varies just after body activity ${ }^{[2,8,12]}$. These variations mostly include continuous and intense activity ${ }^{[10,12]}$.

In this research the subjects, after the last training session, rested for $24 \mathrm{~h}$. However serum sodium of subjects was significant. Mean concentration of subjects' serum sodium increased $2.21 \mathrm{~m} \mathrm{Eq} \mathrm{L}^{-1}$ in post-test than pre-test. It seems that body activity reduces weight of subjects after regular period of training. In this time, sodium and body fluids decreases by sweating. Over sweating causes more water loss and sodium concentration increase in blood. In this regard, present research corresponds with Noakes ${ }^{[10]}$. Also, it seems intensity and training duration affect sodium response and its concentration. On the other hand, blood sampling time after activity is another important factor after training to determine sodium concentration. Comparing serum potassium means did not show significant difference between pre - and post-test stages. It seems $0.13 \mathrm{~m} \mathrm{Eq} \mathrm{L} \mathrm{L}^{-1}$ increase in potassium concentration has been caused by natural variations of serum potassium concentration. In this regard, the present research does not correspond with some researches $^{[1,13]}$.

Furthermore, the subjects` one-day rest time after last training session could return little and nonsignificant serum potassium increase to its original state. The main factor of non- significant in serum potassium was type of intensity and duration of training and also return of extra cellular serum potassium to intra cellular to normalize this electrolyte condition after $24 \mathrm{~h}$ of rest. In present study, in addition, sodium and potassium variables, $12 \mathrm{~min}$ running-jugging distance were performed to determine maximal oxygen consumption. Participants in projects ran distances with certain heart rate. 12 min running-jugging test was performed before the first session and after the last one. Comparing subjects' traversed distance means showed 2 sessions of training per week with certain heart rate intensity can cause significant difference in $\mathrm{VO}_{2}$ max of subjects $(\mathrm{p}=0.0001)$ that corresponds with most research results such as Garrett Kirkendal ${ }^{[4]}(2000)$ and Kooper. 


\section{CONCLUSION}

The subjects' potassium of rest serum had an increased that probably the extra-cellular potassium had returned into the intracellular. The observation suggested that accumulation of extra cellular potassium might be important for the development of fatigue in human muscles. The subjects' $\mathrm{VO}_{2 \max }$ was obtained significant after 16 sessions of training that probably was due to the effectiveness of incremental continuous running. A rise in potassium (hyperkalaemia) is rapidly reversed after rest from exercise and many even associated with a lowering of potassium levels to below control levels.

\section{REFERENCES}

1. Barlows, C.W. and D. Qayyum et al., 1994. Effect of physical training on exercise-induced hyperkalaemia in chronic heart failure: Relation with ventilation and catecholamines. Circulation 89: 1144-1152.

2. Constantinides, C.D., J.S. Gillen, F.E. Boada, M.G. Pomper and P.A. Bottomley, 2000. Human skeletal muscle: Sodium MR imaging and quantificationpotential applications in exercise and disease. Radiology, 216: 559-568.

3. Darrin S., N. Jens-Jung, Jens Bangsbo and Carsten Juel 2005. Metabolic alkalosis reduces exerciseinduced acidosis and potassium accumulation in human skeletal muscle interstitium. J. Physiol., 566: 481-489.

4. Garrett W.E., and D.T. Kirkendal, 2000. Exercise and sport science. Philadelphia: Lippincott Williams \& Wilkins.

5. Jens Jung, N., M. Magni, K. Christina, K. Michael and P. Krustrup et al., 2004. Effect of highintensity intermittent training on potassium kinetics and performance in human skeletal muscle. J. Physiol., 554: 857-870.
6. Kiens, B. and B. Saltin, 1986. Endurance training of man decreases muscle potassium loss during exercise. Acta Phys. Scand., 126: 20A.

7. Mc Kenna, M.J., G.J. Heigenhauser and R.S. Mc Kelvie et al., 1997. Sprint training enhances ionic regulation during intense in men. J. Phyiol., 501: 687-702.

8. Montain, S.J., M.N. Sawka and C.B. Wenger, 2001. Hyponatremia associated with exercise: Risk factors and pathogenesis. Exerc. Sport Sci. Rev., 29: 113-117.

9. Noakes, T.D., 1992. Hyponatremia during endurance running: a physiological and clinical interpretation. Med Sci Sports Exerc., 24:403-5.

10. Noakes, T., 2002. Hyponatremia in distance runners: Fluid and sodium balance during exercise. Curr. Sports Med. Reports, 1: 197-207. Doi: 10.1007/s11932-002-0022-x.

11. Vollestad, N.K., J. Hallen and O.M. Sejerted, 1994. Effect of exercise intensity on potassium balance in muscle and blood in man. The Journal of Physiology., 475: (2) 359-368.

12. Warburton, D. E. R.,R.C. Welsh, M.J. Haykowsky, D.A. Taylor and D.P. Humen, 2002. Biochemical changes as a result of prolonged strenuous exercise. Br. J. Sports Med., 36: 301-303.

13. Yasuhiko, T., M. Ito, H. Yakio, E, Ito and S. Kaoru et al., 1999. Exercise-induced rise in arterial potassium in patients with chronic heart failure, Chest, 116: 88-96. 